\title{
The Use of Autologous Fibroblasts for the Reconstruction of the Anterior Cruciate Ligament Tears
}

\author{
Pedro Guillén-García ${ }^{1,2}$, Elena Rodríguez-Iñigo ${ }^{1}$, Marta Guillén-Vicente ${ }^{1}$, Rosa Caballero-Santos ${ }^{1}$, \\ Isabel Guillén-Vicente ${ }^{1}$, Tomás Fernández-Jaén ${ }^{1,2}$, Steve Abelow ${ }^{3}$, Juan Carlos Izpisua Belmonte ${ }^{4}$, \& \\ Juan Manuel López-Alcorocho ${ }^{1}$ \\ ${ }^{1}$ Biomedical Research Unit, Clinica CEMTRO, Madrid, Spain \\ ${ }^{2}$ Sports Medicine Department, Catholic University of Murcia, Murcia, Spain \\ ${ }^{3}$ Lake Tahoe Sports Medicine Center, South Lake Tahoe, CA, USA \\ ${ }^{4}$ Gene Expression Laboratory, Salk Institute for Biological Studies, La Jolla, CA, USA \\ Correspondence: Juan Manuel López-Alcorocho, Biomedical Research Unit, Clinica CEMTRO, Madrid, Spain. \\ Tel: 34-91-735-5757. E-mail: jm.lopez@amplicel.com
}

Received: March 6, 2015 Accepted: March 17, 2015 Online Published: March 23, 2015

doi:10.5539/ijb.v7n2p126 URL: http://dx.doi.org/10.5539/ijb.v7n2p126

\begin{abstract}
Surgical reconstruction using an autologous or allogenic allograft is the treatment of choice for anterior cruciate ligament (ACL) tear repair. We have checking the treatment of ACL tears with in vitro cultured autologous fibroblasts on porcine type I/III collagen membranes, in 12 sheep randomly assigned to be treated with collagen membrane without cells or with porcine membrane plus 5 million autologous fibroblasts per $\mathrm{cm}^{2}$. The animals underwent a first surgery in which a biopsy of the ACL was taken, and a second one in which the membrane was implanted alone $(\mathrm{N}=6)$ or with the fibroblasts $(\mathrm{N}=6)$ isolated from the biopsy. After 16 weeks, the animals were sacrificed and samples of healthy and repaired ACL were taken for histological and gene expression of type I collagen (COL1), MMP-13 (matrix metallopeptidase 13), and tenascin-C (TNC) studies. The architecture of normal ACL was not conserved either in the ACL treated with the membrane with or without cells. However, a higher degree of peripheral vascularization was observed in the ACL treated with membrane plus fibroblasts than in those treated with membrane alone. Cellularity and nucleus volume were significantly higher in the center or the periphery of the neo-formed ACL than in the control ACL. No differences between the ACL treated with membrane alone or with membrane plus cells were observed in the relative COL1, MMP-13 and tenascin-C expression. Fibroblasts embedded in porcine type I/III membranes probably enhance vascularization of the graft, so it could be a promising tool for the treatment of ACL tears.
\end{abstract}

Keywords: anterior cruciate ligament, fibroblasts, tissue engineering, animal model, vascularization

\section{Introduction}

Anterior cruciate ligament (ACL) tears represent one of the most frequent lesions in the knee. Apart from the ACL tear, we can find some associated lesions such as meniscal, chondral or capsular ligament injuries which may complicate the evolution of the ACL tear (Jiménez-Collado, Guillén-García, \& Sobrado-Pérez, 1994). Currently, the ACL tears are treated with a surgical procedure that implies the use of different tendons or ligaments to reconstruct the damaged ACL (Murawski, van Eck, Irrgang, Tashman, \& Fu, 2014).

In people who practice sports regularly but not professionally, the rupture of the ACL and all the associated injuries leads to a major decline in their quality of life, but it is in the professional athlete where these lesions have a crucial importance. The fundamental reason is the long recovery time, which can range from 6 to 8 months (Bizzini \& Silvers, 2014; Czuppon, Racette, Klein, \& Harris-Hayes, 2014).

Repairing the ACL tear was one of the first alternatives that were proposed for treatment of the ACL rupture, but soon it was seen that this therapy led inexorably to failure. However, reconstruction seeks to avoid instability episodes (Pattee, Fox, Del Pizzo, \& Friedman, 1989) and the deterioration of the joint, which may result in injury to the meniscus and cartilage (Lohmander, Englund, Dahl, \& Roos, 2007; Snoeker, Bakker, Kegel, \& Lucas, 2013) and in early osteoarthritic changes (Lohmander, Englund, Dahl, \& Roos, 2007). The usual treatment of the ACL tear involves the use of an invasive surgical technique, wherein the broken ACL autologous is replaced by other 
biological structures, mostly a tendon anchored to the tibia and femur by drilling. Although both, tendon and ligament are very similar in terms of their structural and cellular composition, they still have different physical and mechanical properties, because their functions are also different (Jiménez-Collado, Guillén-García, \& Sobrado-Pérez, 1994). Therefore, an integration period is required to make the implanted tendon structure assuming the role of ligament, which directly affects the recovery time of the patient (Bizzini \& Silvers, 2014).

Currently, the research on this field is focused in finding a new method to reduce the time of recovery which with these techniques is now of 6-8 months. One alternative method could be the treatment of these lesions with tissue engineering (Nau, \& Teuschl, 2015). We have investigated a novel tissue engineering approach based in the use of ACL isolated fibroblasts combined with type I/III collagen membranes as a carrier in the reconstruction of broken ACL. This biomaterial has been widely used as a carrier for other cell types such as chondrocytes for cartilage repair (D. Goyal, A. Goyal, Keyhani, Lee, \& Hui, 2013; Rodriguez-Merchan, 2013). We firstly described a method to isolate and culture these cells from ACL biopsies from patients with ACL tears, without losing their biological properties (Guillén et al., 2013). In a second phase, we carried-out a study in the sheep model, to check the use of the fibroblasts combined with the collagen membrane. The aim of this study was to compare the efficacy in the animal model of the suture and the combination of suture plus autologous fibroblast implantation for the treatment of the ACL tears.

\section{Material and Methods}

\subsection{Animals}

Twelve 2-3 years-old female sheep (Ovis aries L, var. Merino Fleischaf) were included in this study. The experimental protocol was approved by the Ethical Committee of our Institution. The animals were randomly assigned to one of the following groups:

Group 1; treated with traditional suture and a resorbable porcine collagen type I/III membrane (Chondro-Gide, Geistlich Biomaterials, Wolhusen, Switzerland)

$\underline{\text { Group 2; }}$; treated with traditional suture plus 5 million autologous fibroblasts per $\mathrm{cm}^{2}$, seeded in the collagen type I/III membrane

\subsection{ACL Biopsy Obtaining}

General anesthesia was induced with $4 \mathrm{mg} / \mathrm{kg}$ body weight intravenous propophol (Propophol-Lipuro® ${ }^{\circledR} \%$; B. Braun Medical International; Rubi; Spain) and maintained with 2-3\% isofluorane (Isoba ${ }^{\circledR}$ vet; Shering-Plough; Kenilworth; NJ).

A parapatellar incision was made to expose the right knee joint and the patella was laterally dislocated. Once the ACL was exposed, a sample was taken from all the animals. The sample was placed in a tube with $25 \mathrm{ml}$ of Dulbeco's Modified Eagle's Medium (DMEM) (Lonza Group Ltd., Basel, Switzerland) and immediately processed. The joint was closed with $\# 0$ Vicryl ${ }^{\circledR}$, the subcutaneous tissue with $2 / 0$ Vicryl ${ }^{\circledR}$ and the skin with staples.

After surgery the animals received antibiotic prophylaxis with $10 \mathrm{mg} / \mathrm{Kg}$ sodium cephalexin (Ceporex®; Shering-Plough) and analgesic with $4 \mathrm{mg} / \mathrm{Kg}$ carprofen (Rimadyl ${ }^{\mathbb{B}}$; Pfizer) and $0.01 \mathrm{mg} / \mathrm{Kg}$ buprenorphine (Buprex ${ }^{\circledR}$, Shering-Plough). The animals were observed daily after surgery and any relevant physical sign or symptom revealing pain was carefully monitored and followed-up.

\subsection{Isolation and Culture of Fibroblasts}

Each ACL sample was placed in a petri dish and cut into small fragments using a sterile razor blade. The fragments were carefully disposed in a sterile $50 \mathrm{ml}$ tube and isolation of cells was performed by enzymatic digestion with 1 $\mathrm{mg} / \mathrm{ml}$ collagenase (Roche Diagnostics $\mathrm{GmbH}$, Mannheim, Germany) at $37^{\circ} \mathrm{C}$ overnight. The digested samples were filtered through a $70 \mu \mathrm{m}$ gauge nylon cell strainer (BD Falcon, Franklin Lakes, NJ) connected to a clean 50 $\mathrm{ml}$ tube. The cell strainer was washed with $10 \mathrm{ml}$ of DMEM. The sample was centrifuged for 5 minutes at 1,800 rpm and room temperature, the supernatant was discarded and additional $20 \mathrm{ml}$ of DMEM were added to the tube. The tube was centrifuged for 5 minutes at 1,500 rpm and room temperature, the supernatant was discarded and the pellet was resuspended in DMEM supplemented with $10 \%$ of fetal bovine serum (Lonza), L-Glutamine and penicillin-streptomicin. The number of viable cells was estimated with the trypan-blue exclusion method in a Neubauer's chamber.

The cells were transferred to a culture flask at a density of $1,000-5,000$ viable cells per $\mathrm{cm}^{2}$ with complete DMEM and incubated at $37^{\circ} \mathrm{C}, 5 \% \mathrm{CO}_{2}$ and $95 \%$ relative humidity. When the culture reached $80 \%$ confluence the cells were detached with $0.05 \mathrm{ml} / \mathrm{cm}^{2}$ of $200 \mathrm{mg} / \mathrm{l}$ trypsin-EDTA. 


\subsection{ACL Tear Induction and Fibroblast Implantation}

Fifteen days after the first surgery, the animals underwent a second surgery, carried-out under general anesthesia and using the same surgical procedure as described in a previous section. During surgery, the ACL was exposed and two stitches (proximal and distal) were practiced to avoid losing the ACL ends after cutting the ligament (Figure 1a). Then, the ACL was dissected with a ladder-shaped cut within both stitches (Figure 1b).
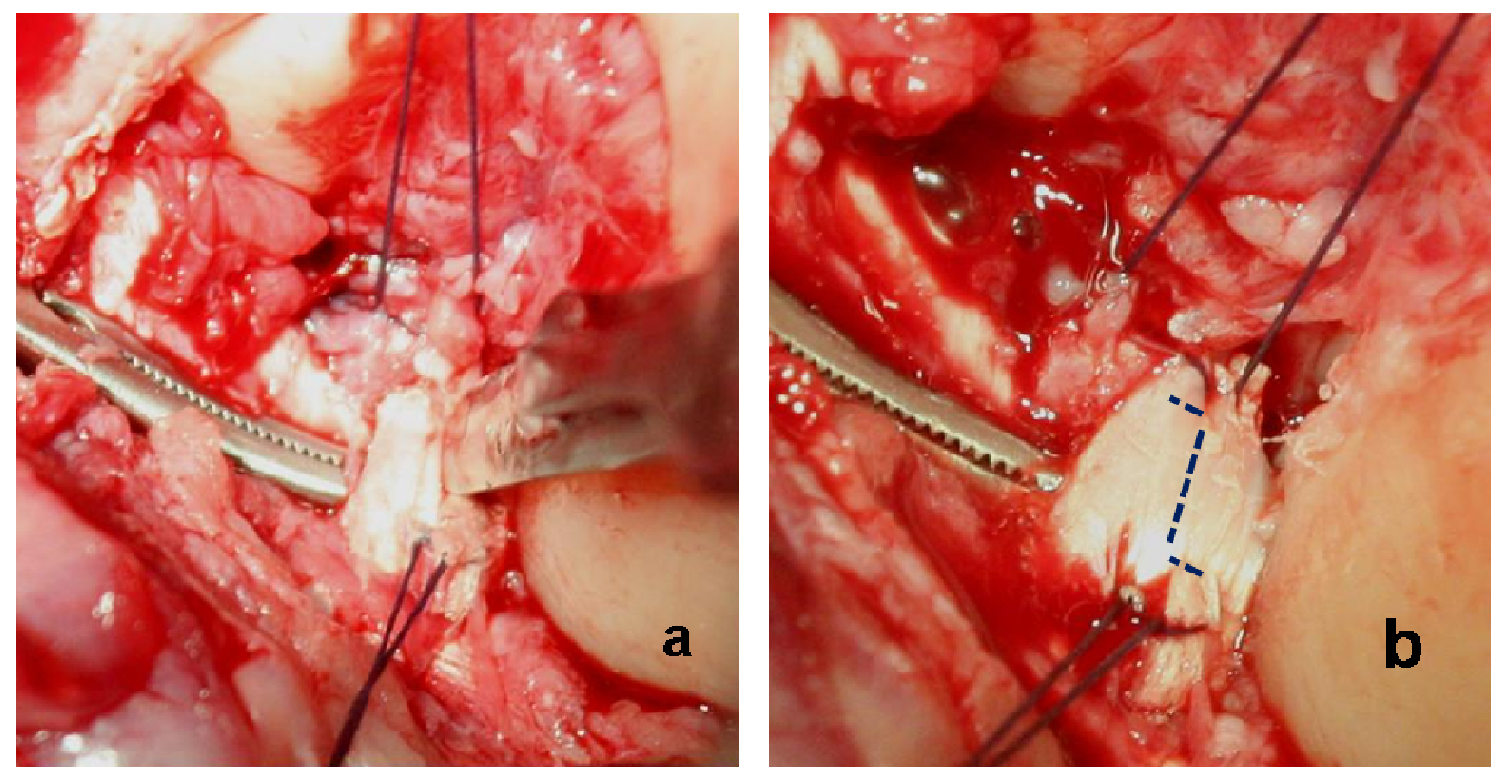

Figure 1. After ACL exposition, a proximal and a distal stitched were practiced (a) and the ACL was then dissected by cut it between the two stitches (b)

For each animal, a fragment of $1 \mathrm{~cm}^{2}$ of the porcine type I/III collagen membrane was cut out. Each fragment was prepared for its implantation by giving four cardinal suture points (Figure 2a). For the animals of the Group 1, the membrane fragments with the four stitches were seeded with DMEM without cells, while the membrane fragments for the animals of the Group 2 were seeded with 5 million of autologous fibroblasts (cell density: 1 million cells per $\mathrm{cm}^{2}$ ) in DMEM as a vehicle. After waiting 10 minutes, the cells were adsorbed onto the membrane, and then it was placed below the ends of the ligament, with the face in which the cells or the vehicle was deposited in contact with the ruptured ACL (Figure 2b). Once the membrane was placed in the correct place, the ends of the sutures (proximal and distal) applied in the ACL at the beginning of the intervention, were tied (Figure 2c). The membrane was then closed by tying the cardinal stitches two by two and by continuous suture with $6 / 0$ Vicryl $^{\circledR}$ (Figure 2d). The joint and adjacent tissues were closed as described above. All the animals were followed-up daily for any relevant sign of pain. After surgery the animals received antibiotic prophylaxis and analgesic as described in a previous paragraph.

\subsection{Necropsy}

After a period of 16 weeks, the animals were sacrificed and in each animal 2 different samples were taken. A sample of healthy ACL was taken from the left knee and other sample of the repaired ACL was taken from the right knee. A little part of each sample was cut-out and stored in RNALater (Life Technologies S.A., Madrid, Spain) at $-20^{\circ} \mathrm{C}$ until it was used for molecular study by real time polymerase chain reaction (RT-PCR). The remaining tissue was preserved in $10 \%$ formaldehyde for histological study.

\subsection{Real-Time Quantitative Polymerase Chain Reaction (RT-PCR)}

\subsubsection{Isolation of Total RNA}

After RNALater removal, RNA was isolated after treatment with TRIzol (Invitrogen) and chloroform and isopropanol precipitation, following the manufacturers' instructions. The concentration of the RNA resuspended in RNase free water was measured using a NanoDrop 1000 (NanoDrop Technologies, Inc., Wilmington, DE) and the final concentration was adjusted to $1 \mu \mathrm{g} / \mu \mathrm{l}$. 

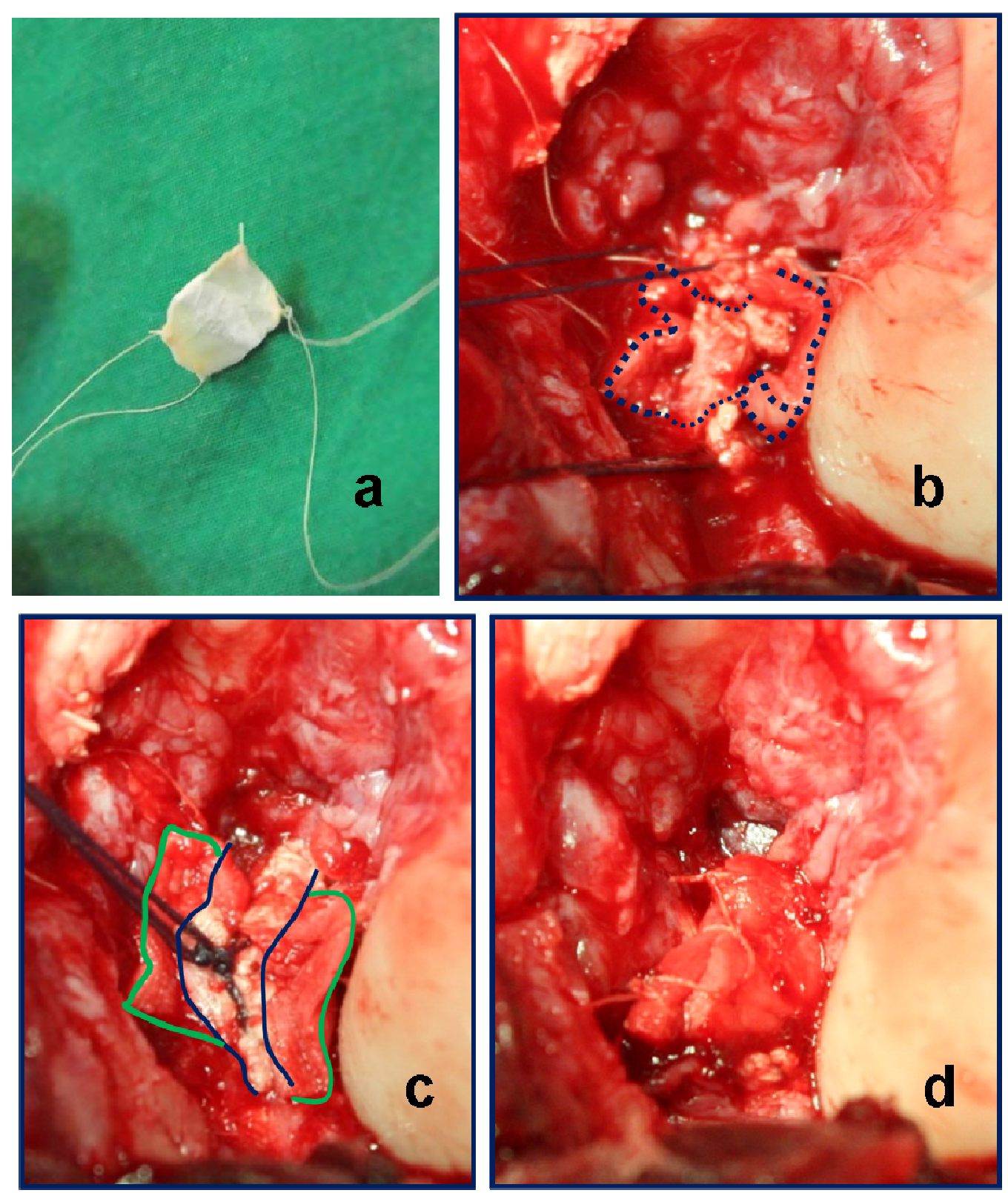

Figure 2. For ACL tear repair, each fragment of $1 \mathrm{~cm}^{2}$ of the porcine type I/III collagen membrane was prepared giving four cardinal suture points (a). The membrane with or without fibroblasts was placed below the ends of the ligament (b), the ends of the sutures (proximal and distal) were tied (c) and finally the membrane was then closed by tying the cardinal stitches two by two and by continuous suture (d)

\subsection{2 cDNA Synthesis}

RNA was reversed-transcribed using random hexanucleotides with the First Strand cDNA Synthesis Kit for RT-PCR (AMV) (Roche Diagnostics GmbH) following the manufacturers' instructions.

\subsubsection{Real-Time PCR}

The relative expression of type I collagen (COL1) gene, MMP-13 (matrix metallopeptidase 13) gene, which encoded for collagenase 3, and tenascin-C (TNC) gene was determined by real-time PCR (RT-PCR) in a LightCycler ${ }^{\circledR} 1.5$ (Roche Molecular Biochemicals, Mannheim, Germany) using the expression of the $\beta$-actin housekeeping gene as standard. Each gene was amplified using the specific primers and probes designed by the Universal Probe Library (UPL) system (Roche Molecular Biochemicals). The nucleotide sequence of each primer pair and UPL is shown in the Table 1. 
Table 1. Sequence and location of the primers used in this study

\begin{tabular}{|c|c|c|c|c|}
\hline Gene (Accession Number) & & Primer Sequence & $\begin{array}{l}\text { Nucleotide } \\
\text { Position }\end{array}$ & $\begin{array}{l}\text { Number } \\
\text { of UPL } \\
\text { Probe }\end{array}$ \\
\hline \multirow[t]{3}{*}{ COL1 (NM_000088.3) } & & & & \#67 \\
\hline & Forward & GGGATTCCCTGGACCTAAAG & $1866-1885$ & \\
\hline & Reverse & GGAACACCTCGCTCTCCA & $1911-1928$ & \\
\hline \multirow[t]{3}{*}{ MMP13 (GQ221063.1) } & & & & \# 34 \\
\hline & Forward & СССТTCCCATGACCTTATCTT & $1020-1040$ & \\
\hline & Reverse & CATAACCACTAAGTGCCCAAAA & $1060-1081$ & \\
\hline \multirow[t]{3}{*}{ Tenascin-C (XM_004005200.1) } & & & & \# 9 \\
\hline & Forward & TCGACAAGGACACAGACTCG & $6542-6561$ & \\
\hline & Reverse & AGAAAGCCCCCTTGTAGGAC & $6582-6601$ & \\
\hline \multirow[t]{3}{*}{$\beta$-actin (AF035422.1) } & & & & \# 122 \\
\hline & Forward & ATCACCATCGGCAATGAAC & $400-418$ & \\
\hline & Reverse & CAGGAAGGAAGGCTGAAG & $441-459$ & \\
\hline
\end{tabular}

Note: The relative position of the primers is referred to the nucleotide sequence of the accession number. COL1: type I collagen; MMP13: metallopeptidase 13.

All the amplifications were carried-out using the LightCycler ${ }^{\circledR}$ TaqMan ${ }^{\circledR}$ Master kit (Roche Molecular Biochemicals), following the instructions given by the manufacturer with slight modifications. The PCR method has been described elsewhere (Guillén-García et al., 2014). Briefly, for each gene, the reaction mixture was composed by $1 \mu \mathrm{M}$ of forward and reverse primer, $2 \mu \mathrm{l}$ of UPL probe, $1 \mathrm{x}$ Master Mix and $2 \mu \mathrm{l}$ of cDNA. The reaction profile was composed by a preincubation module at $95^{\circ} \mathrm{C}$ for $10 \mathrm{~min}$ and an amplification one with the following steps (repeated 45 cycles): denaturation at $95^{\circ} \mathrm{C}$ for $10 \mathrm{sec}$, annealing at $60^{\circ} \mathrm{C}$ for $30 \mathrm{sec}$ and extension at $72^{\circ} \mathrm{C}$ for $1 \mathrm{sec}$, with a single fluorescence acquisition step. Each sample was tested in duplicate and all genes were studied in the same PCR run. The expression of COL1, MMP13 and tenascin-C referred to that of the housekeeping $\beta$-actin gene was automatically calculated using the Relative Quantitation module of LightCycler 1.5 software.

\subsection{Histological Analysis}

The biopsies were embedded in paraffin and 4- $\mu$ m-thick sections were cut using a microtome. The sections were stained with hematoxylin- eosin to study the tissue architecture. Morphometric studies were performed in order to quantify cellularity in all histologic samples. The number of cells per surface unit was quantified in ACL histologic sections stained with hematoxylin-eosin, using the image analysis software Leica QWin. For each sample a $1 \mathrm{~mm}^{2}$ was analysed, from a representative tissue area, using sequential images taken with a digital camera DC300 paired to an optical microscope Leica DM5000B at 20x magnification.

\subsection{Statistical Analysis}

Statistical analysis was performed using the IBM SPSS Statistics version 22 software. Continuous variables were expressed as the mean \pm standard deviation and the normality was checked with the Kolmogorov-Smirnov Test. ANOVA was used comparison of means when the variables had a normal distribution. In this case, two-by-two comparisons were done with the Tukey's Test. Non-parametric Kruskall-Wallis and the Mann-Whitney U Tests were used to compare non-normal continuous distributions. Categorical variables were expressed as counts and/or percentage and compared with the Chi-Square Test. In all comparisons and parameter estimation a value of $\mathrm{p}<0.05$ (two-sides) were considered statistically significant.

\section{Results}

After the necropsy, the morphological macroscopic aspect of the operated ACL was studied in each animal. Only in two animals, one from the group treated with the membrane alone and other form the group treated with membrane plus cells, the ACL was thinner than the normal ACL taken from the non-operated limb. In the remaining cases, the macroscopic aspect of the repaired ACL was normal (data not shown).

The relative expression of COL1, MMP13 and tenascin-C of the ACL repaired with membrane compared with that of the ACL repaired with membrane plus fibroblasts is depicted in the Figure 3. As shown in the figure, no significant differences in the expression of any of the 3 genes were observed when ACL treated with or without 
fibroblasts were compared. The expression levels of the 3 proteins were similar when both limbs, the operated limb and the non-operated one, were compared as a whole (Table 2). We did not find significant differences when both limbs were compared in each group of treatment separately (Table 2).

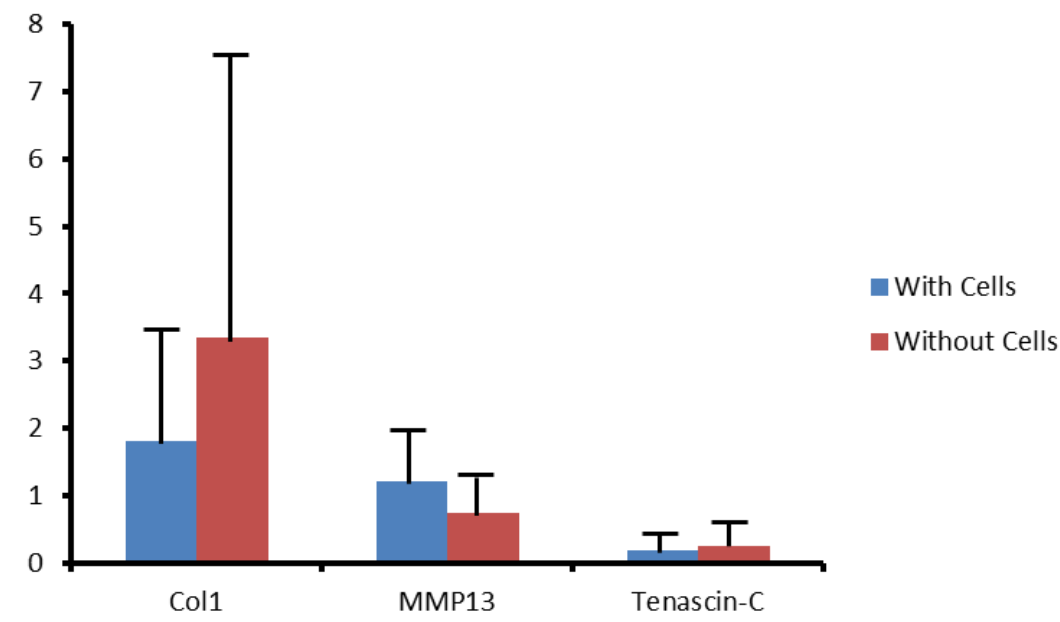

Figure 3. Relative expression of type I collagen, MMP13 and tenascin-C of the ACL repaired with membrane compared with that of the ACL repaired with membrane plus fibroblasts

Table 2. Type I Collagen, MMP13 and tenascin-C expression profile comparing operated vs. non-operated limbs. All the values are expressed as the mean \pm standard deviation. All the comparisons were performed using the Man Whitney U test

\begin{tabular}{lccccccccc}
\hline & & & \multicolumn{3}{c}{ MEMBRANE ALONE } & \multicolumn{3}{c}{ MEMBRANE + FIBROBLASTS } \\
\cline { 2 - 10 } & $\begin{array}{c}\text { Operated } \\
\text { limb (N=10) }\end{array}$ & $\begin{array}{c}\text { Non-operated } \\
\text { limb (N=10) }\end{array}$ & p-value & $\begin{array}{c}\text { Operated } \\
\text { limb (N=5) }\end{array}$ & $\begin{array}{c}\text { Non-operated } \\
\text { limb (N=5) }\end{array}$ & p-value & $\begin{array}{c}\text { Operated } \\
\text { limb (N=5) }\end{array}$ & $\begin{array}{c}\text { Non-operated } \\
\text { limb (N=5) }\end{array}$ & p-value \\
\hline COL1 & $2.42 \pm 2.85$ & $2.62 \pm 2.71$ & 0.796 & $3.34 \pm 4.20$ & $2.07 \pm 2.54$ & 0.686 & $1.81 \pm 1.68$ & $2.99 \pm 2.99$ & 0.485 \\
MMP13 & $0.21 \pm 0.20$ & $0.66 \pm 2.85$ & 0.105 & $0.26 \pm 0.21$ & $0.44 \pm 0.39$ & 0.686 & $0.18 \pm 0.21$ & $0.81 \pm 1.15$ & 0.093 \\
Tenascin-C & $1.02 \pm 0.71$ & $1.15 \pm 1.24$ & 0.481 & $0.74 \pm 0.54$ & $0.88 \pm 0.68$ & 1.000 & $1.21 \pm 0.80$ & $1.33 \pm 1.54$ & 0.310 \\
\hline
\end{tabular}

Hematoxylin-eosin staining revealed that the architecture of normal ACL was not conserved either in the ACL treated with the membrane with or without cells (Figure 4). In both neo-formed structures, a number, apparently higher than in the control tissue, of fibroblasts-like cells were observed (Figure 4). However, when the periphery of the neo-formed structures were examined, a higher degree of peripheral vascularization was observed in the ACL treated with membrane plus fibroblasts (Figure 5a) than in that treated with membrane alone (Figure 5b). In the histological sections we noticed that in both neo-formed ACL, the number of cells was quite different when the center and the periphery of the structure were compared. To assess this apparent difference found between the center and the periphery, the tissue cellularity, measured by the number of nucleus per $\mathrm{mm}^{2}$, was estimated in the neo-formed ACL. In all the samples, the nucleus volume was estimated by measuring the surface per nucleus. The cellularity was statistically different when the control of the non-operated limbs and both the center and the periphery of the operated limbs were compared ( $\mathrm{p}=0.0001$; Kruskal Wallis test) (Figure 6a). The nucleus volume was also significantly different among control limbs and center and periphery of the operated limbs $(\mathrm{p}=0.0001$; ANOVA) (Figure 6b). The results of the two-by-two comparisons between the control ACL and the center and the periphery of the neo-formed ACL, with respect to the cellularity and the nucleus volume showed no differences between the center and the periphery in both the mean of cellularity and that of the nucleus volume. However, the cellularity was significantly higher in the center or the periphery of the neo-formed ACL than in the control ACL (Figure 6a) and nucleus volume was also higher in the center and the periphery of the reconstructed ACL than in the control (Figure 6b). Finally, when the cellularity and the nucleus volume in the center and in the periphery were compared, no statistically significant differences between the treatment with membrane alone or with membrane plus fibroblasts were found (Table 3). 


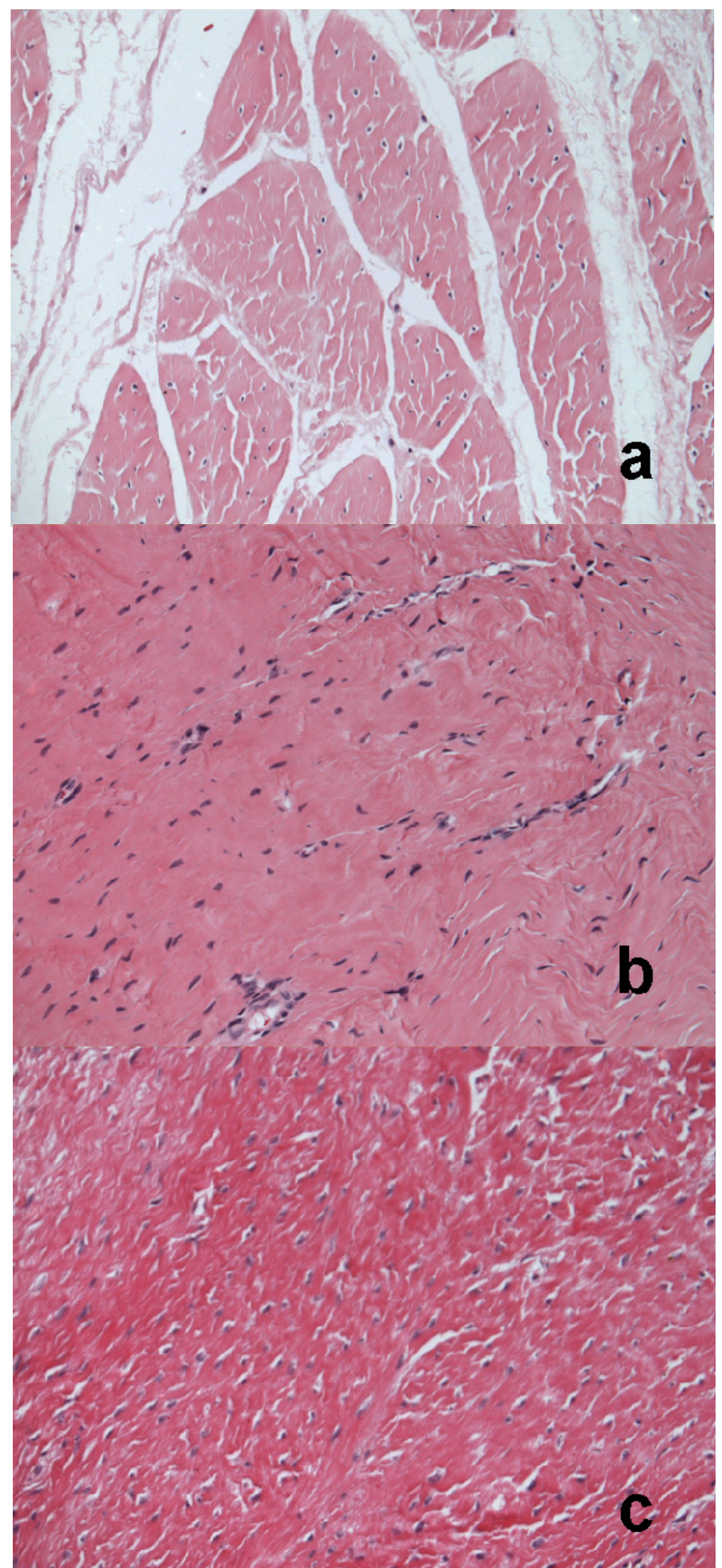

Figure 4. Hematoxylin-eosin staining of the control (a) and the neo-formed ACL treated with the porcine type I/III collagen membrane alone (b) or with fibroblasts (c). Magnification $200 \times$ 


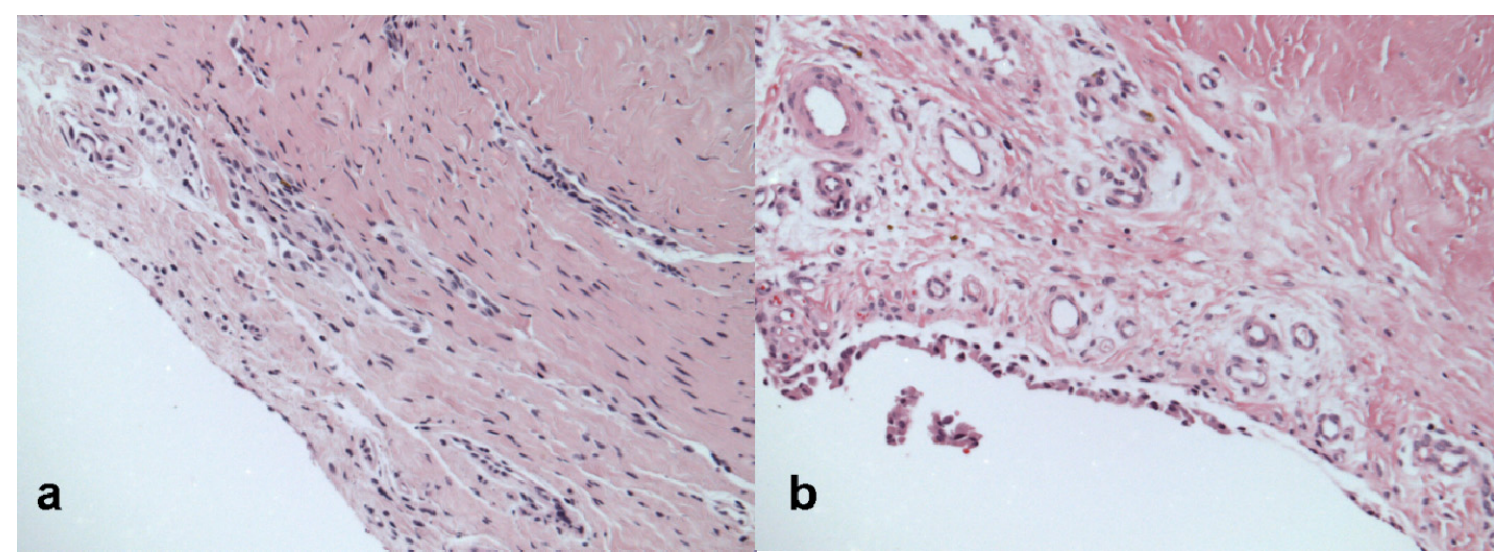

Figure 5. Periphery area of the neo-formed ACL treated with the porcine type I/III collagen membrane alone (a) or with fibroblasts (b). Magnification 200×
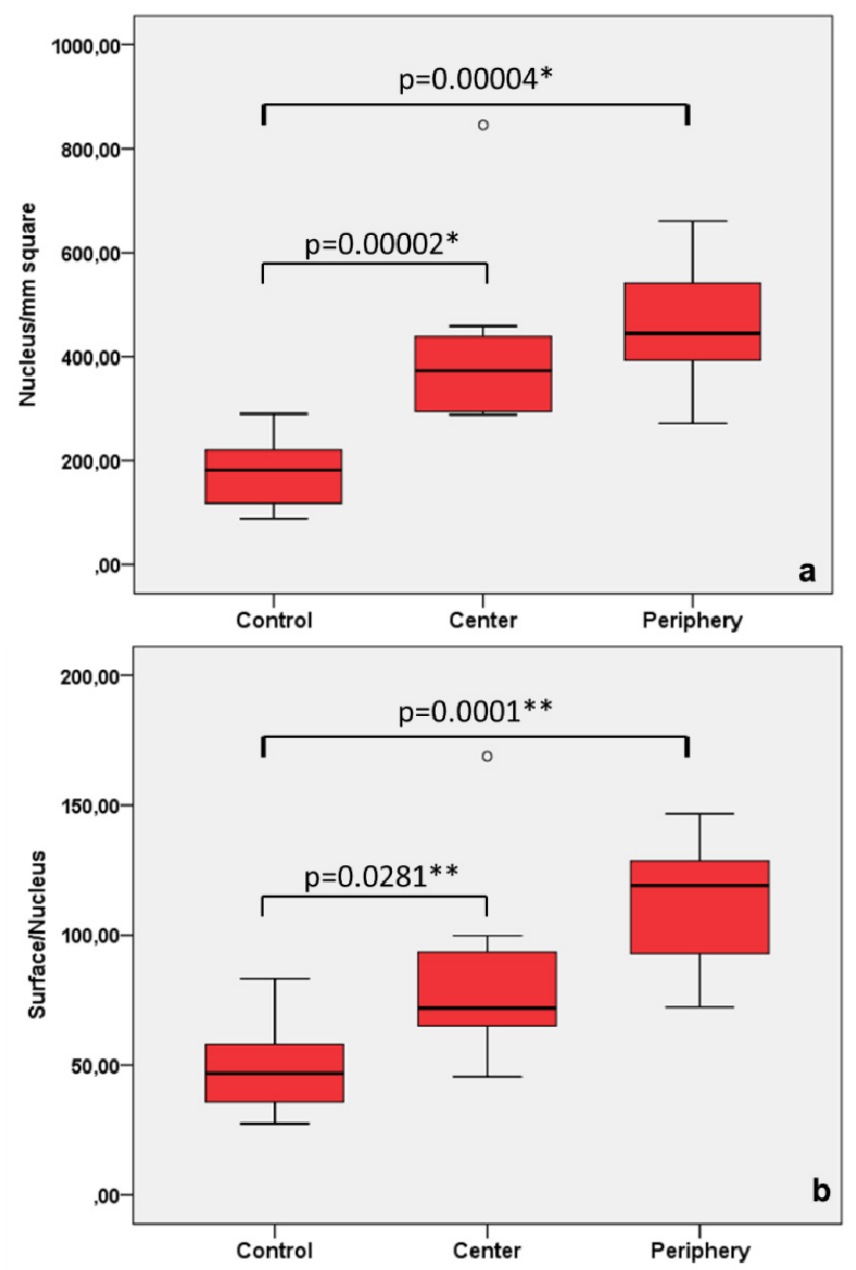

Figure 6. Cellularity (measured as the number of nucleus per mm2) (a) and cell volume (measured as the surface per nucleus) (b) of the control ACL (taken from the non-operated limb) and the center and the periphery of the neo-formed ACL. *Mann-Whitney U test; **Tukey's test 
Table 3. Cellularity expressed as the nucleus per $\mathrm{mm}^{2}$ and nucleus volume measured by the surface per nucleus in the neo-formed ACL after repair with membrane alone or with membrane plus fibroblasts. All the values are expressed as the mean \pm standard deviation. The comparisons were performed using the Man Whitney $U$ test

\begin{tabular}{lcccccc}
\hline & \multicolumn{3}{c}{ CENTER } & \multicolumn{3}{c}{ PERIPHERY } \\
\cline { 2 - 8 } & $\begin{array}{c}\text { Membrane } \\
\mathbf{( N = 5 )}\end{array}$ & Membrane + cells (N=5) & p-value & $\begin{array}{c}\text { Membrane } \\
(\mathbf{N}=\mathbf{5})\end{array}$ & Membrane + cells (N=5) & p-value \\
\hline Nucleus/mm & & & & & \\
\hline Surface/nucleus & $744.80 \pm 58.61$ & $451.29 \pm 205.33$ & 0.352 & $526.36 \pm 131.90$ & $418.02 \pm 98.13$ & 0.286 \\
\hline
\end{tabular}

\section{Discussion}

In the last years, the advances in the field of regenerative medicine and tissue engineering have increased the research and development of new methods to repair the ACL tears. These novel techniques are being used since more than a decade with a relatively high success in other musculoskeletal diseases, such as the articular cartilage lesions (D. Goyal, A. Goyal, Keyhani, Lee, \& Hui, 2013; Rodriguez-Merchan, 2013; Guillén-Garcia et al., 2014; Demoor et al., 2014). In this work we present in an animal model a new tissue engineering-based technique to treat the ACL tears. This technique consists on the use of autologous fibroblasts seeded onto porcine type I/III collagen membranes. These membranes have been widely used as a carrier of autologous chondrocytes to treat articular cartilage injuries (Bentley et al., 2013; D. Goyal, A. Goyal, Keyhani, Lee, \& Hui, 2013; Guillen et al., 2013; Demoor et al., 2014).

In a previous work we demonstrated that the fibroblasts could be seeded onto this membrane without losing their biological properties (Guillen et al., 2013). Other authors had developed other biomaterials made of collagen fibrils and found that the fibroblasts did not lose their features in these biomaterials and thus, they can be used as carriers for constructing ACL analogs (Dunn, Liesch, Tiku, \& Zawadsky, 1995; Bellincampi, Closkey, Prasad, Zawadsky, \& Dunn, 1998). The first thing we noticed was that the ACL treated with or without cells was morphological similar than the control one, in all the cases except in two, one from each group. This result indicates that the ACL has a self-healing potential without cells. In fact, there are some recent studies that points-out to the idea of the self-healing of the ACL breakage, although this capacity is probably limited (Fujimoto, Sumen, Ochi, \& Ikuta, 2002; Kohl et al., 2013) and may be influenced by acute phase inflammatory mediators such as the tumor necrosis factor alpha (TNF- $\alpha$ ) (Xie et al., 2014). The healing efficiency is mediated by the fibroblastic lysyl oxidase enzyme, which function is to catalyze the cross-linking between the collagen and the elastin and whose activity increases with the levels of TNF- $\alpha$ (Xie et al., 2014). As in our experiments, the dissection of the ACL and the repair was done in the same surgical procedure; this acute-phase healing mechanism above described could explain that both neo-formed ACL had the same macroscopic aspect.

We have observed that the ACL repaired with both membrane grafts (with or without fibroblasts) had the same relative expression of COL1, MMP-13 and tenascin-C and moreover the expression levels of both repaired tissues were similar to those found in the control ACL taken form the non-operated limb. This result, which is supported by other author's publications (Dunn, Liesch, Tiku, \& Zawadsky, 1995; Bellincampi, Closkey, Prasad, Zawadsky, \& Dunn, 1998) shows that in both cases the cells of the neo-formed tissue could be similar to those of the normal ACL and these fibroblasts may preserve their biological properties, at least in terms of their mRNA expression profiles.

The neo-formed tissues were studied microscopically and compared to the control ACL. Hematoxylin-eosin staining revealed that both types of neo-formed ACL were made of a tissue, without the structure of a normal ACL, but with fibroblast-like cells very similar to those observed in the normal ACL but in a lower number. Furthermore, the cellularity was statistically significant higher in the neo-formed ACL than in the control. This result could be explained by the migration of fibroblasts from the healthy tissue to the graft implanted to repair the ACL. In this sense, some studies have been published concerning the migration of the fibroblasts form the normal ACL to different scaffolds. Yan et al. (1999) demonstrated that fibroblasts could migrate from healthy ACL areas to damaged tissue and they can adhere to types I and III collagen fibers to help for ligament healing. Murray \& Martin (2000) published that intrinsic fibroblasts migrated from healthy ACL to collagen-glycosaminoglycan scaffolds. These authors demonstrated that certain growth factor such as TGF- $\beta 1$ (Transforming Growth Factor type $\beta 1$ ), PDGF-AB (Platelet Derived Growth Factor type AB), EGF (Epidermal Growth Factor), or FGF-2 (Fibroblast Growth Factor type 2) could influence the migration of fibroblasts, so these factors could be contributing factors for the ligament healing (Meaney Murray, Rice, Wright, \& Spector, 2003). Moreover, the nucleus volume of the neo-formed tissue, 
independently of the location (center or periphery) was higher than in the intact ACL, suggesting that the fibroblasts of the grafts have a high mitotic potential. As stated above, these fibroblasts probably come from the healthy tissue to the graft in the case of the treatment with the membrane alone, and in the case of the membrane plus cells treatment, a number of them come from the healthy tissue and the remaining fibroblasts are from the membrane itself. However, with our experiments we can not determine the origin of the fibroblasts.

Interestingly, we have also found that the only difference between the treatment with the membrane with or without cells was in the periphery of the neo-formed tissue, where the vascularization degree was higher in the treatment with cells than in that without cells. It has been widely published that the revascularization of the tendon graft after ACL reconstruction by surgery is a crucial step in the "ligamentization" process (Arnoczky, Tarvin, \& Marshall, 1982; Butler et al., 1989; Petersen et al., 2003; Yoshikawa et al., 2006). In fact, some techniques have been described trying to enhance both the revascularization and the proprioception after ACL reconstruction preserving the tibial and/or femoral stumps, which can benefit the patient (Lee, Kwon, Kim, Choi, \& Min, 2008; Song et al., 2013; Nag \& Gupta, 2014). Revascularization is one of the first processes that must occur for a successful integration of the tendon after ACL reconstruction (Tohyama, Yoshikawa, Ju, \& Yasuda, 2009). Yoshikawa et al. (2006) have demonstrated in the rabbit model that in proliferating fibroblasts the vascular endothelial growth factor (VEGF) is highly expressed by proliferating fibroblasts, and furthermore it has been also published that VEGF is released by the fibroblasts of the ACL remnants (Xie, Huang Fu, \& Zhao, 2012). As in our work we preserved the remnants in both groups of animals, one can expect that the revascularization were the same in both the animals treated with the membrane alone or with the membrane plus the cells. As the only difference between both groups was the presence of fibroblasts in the membrane, it is likely that these cells could be the responsible for this high degree of vascularization found. However, either the ligamentous or mesenchymal origin of these cells can not be discarded with the results found in the present work. All these facts will be further demonstrated in future research.

To find novel treatments based using tissue engineering methods is a big challenge and becomes in a multidisciplinary science. The findings of all of them would allow us to know better the structure and the biochemical properties of the ACL for developing a good treatment, reducing the morbidity associated to the current one and trying to short the recovery time. In this work we report a novel method for ACL repair using fibroblast and a collagen membrane as a carrier. This method could be a promising tool to treat these lesions as it seems that improves vascularization of the graft. This latter fact will be demonstrated in future research using immunohistochemistry staining against endothelial cells. Furthermore, further investigation will be performed to elucidate the mechanisms for revascularization and the mechanical properties of the graft.

\section{Acknowledgments}

This study has been supported by a grant from the Fundación Pedro Guillén.

\section{References}

Arnoczky, S. P., Tarvin, G. B., \& Marshall, J. L. (1982). Anterior cruciate ligament replacement using patellar tendon. An evaluation of graft revascularization in the dog. Journal of Bone and Joint Surgery (American), 64, 217-224.

Bellincampi, L. D., Closkey, R. F., Prasad, R., Zawadsky, J. P., \& Dunn, M. G. (1998). Viability of fibroblast-seeded ligament analogs after autogenous implantation. Journal of Orthopedics Research, 16, 414-420.

Bentley, G., Bhamra, J. S., Gikas, P. D., Skinner, J. A., Carrington, R., \& Briggs, T. W. (2013). Repair of osteochondral defects in joints--how to achieve success. Injury, 44(Suppl 1), S3-S10. http://dx.doi.org/10.1016/S0020-1383(13)70003-2.

Bizzini, M., \& Silvers, H. J. (2014). Return to competitive football after major knee surgery: more questions than answers? Journal of Sports Sciences, 32, 1209-1216. http://dx.doi.org/10.1080/02640414.2014.909603

Butler, D. L., Grood, E. S., Noyes, F. R., Olmstead, M. L., Hohn, R. B., Arnoczky, S. P., \& Siegel, M. G. (1989). Mechanical properties of primate vascularized vs. nonvascularized patellar tendon grafts; changes over time. Journal of Orthopedic Research, 7, 68-79.

Czuppon, S., Racette, B. A., Klein, S. E., \& Harris-Hayes, M. (2014). Variables associated with return to sport following anterior cruciate ligament reconstruction: a systematic review. British Journal of Sports Medicine, 48, 356-364. http://dx.doi.org/10.1136/bjsports-2012-091786 
Demoor, M., Ollitrault, D., Gomez-Leduc, T., Bouyoucef, M., Hervieu, M., Fabre, H., ... Galera, P. (2014). Cartilage tissue engineering: molecular control of chondrocyte differentiation for proper cartilage matrix reconstruction. Biochimica et Biophysica Acta, 1840, 2414-2440. http://dx.doi.org/10.1016/j.bbagen. 2014.02.030

Dunn, M. G., Liesch, J. B., Tiku, M. L., \& Zawadsky, J. P. (1995). Development of fibroblast-seeded ligament analogs for ACL reconstruction. Journal of Biomedical Material Research, 29, 1363-1371.

Fujimoto, E., Sumen, Y., Ochi, M., \& Ikuta, Y. (2002). Spontaneous healing of acute anterior cruciate ligament (ACL) injuries - conservative treatment using an extension block soft brace without anterior stabilization. Archives of Orthopaedic and Trauma Surgery, 122, 212-216.

Goyal, D., Goyal, A., Keyhani, S., Lee, E. H., \& Hui, J. H. (2013). Evidence-based status of second- and third-generation autologous chondrocyte implantation over first generation: a systematic review of level I and II studies. Arthroscopy, 29, 1872-1878. http://dx.doi.org/10.1016/j.arthro.2013.07.271

Guillén, P., Rodríguez-IÍñgo, E., Guillén-Vicente, I., Caballero-Santos, R., Guillén-Vicente, M., García-Gómez, F., ... López-Alcorocho J.M. (2013). Pilot study on the anterior cruciate ligament (ACL) reconstruction with autologous fibroblasts culture on collagen I/III membranes. Revista Trauma Fundación MAPFRE, 24, 33-38.

Guillén-García, P., Rodríguez-Iñigo, E., Guillén-Vicente, I., Caballero-Santos, R., Guillén-Vicente, M., Abelow, S., ... López-Alcorocho, J.M. (2014). Increasing the dose of autologous chondrocytes improves articular cartilage repair: histological and molecular study in the sheep animal model. Cartilage, 5, 114-122. http://dx.doi.org/10.1177/1947603513515903

Jiménez Collado, J., Guillén García, P., \& Sobrado Pérez, J. (1994). Rodilla: morfogénesis, anatomía clínica y vías de acceso. Madrid: Mapfre (Ed.).

Kohl, S., Evangelopoulos, D.S., Kohlhof, H., Hartel, M., Bonel, H., Henle, P., ... Eggli, S. (2013). Anterior crucial ligament rupture: self-healing through dynamic intraligamentary stabilization technique. Knee Surgery Sports Traumatology Arthroscopy, 21, 599-605. http://dx.doi.org/10.1007/s00167-012-1958-x

Lee, B.-I., Kwon, S.-W., Kim, J.-B., Choi, H.-S., \& Min, K.-D. (2008). Comparison of clinical results according to amount of preserved remnant in arthroscopic anterior cruciate ligament reconstruction using quadrupled hamstring graft. Arthroscopy, 24, 560-568. http://dx.doi.org/10.1016/j.arthro.2007.11.011

Lohmander, L. S., Englund, P. M., Dahl, L. L., \& Roos, E. M. (2007). The long-term consequence of anterior cruciate ligament and meniscus injuries: osteoarthritis. American Journal of Sports Medicine, 35, 1756-1769.

Meaney Murray, M., Rice, K., Wright, R. J., \& Spector, M. (2003). The effect of selected growth factors on human anterior cruciate ligament cell interactions with a three-dimensional collagen-GAG scaffold. Journal of Orthopedic Research, 21, 238-244.

Murawski, C. D., van Eck, C. F., Irrgang, J. J., Tashman, S., \& Fu, F. H. (2014). Operative treatment of primary anterior cruciate ligament rupture in adults. Journal of Bone \& Joint Surgery, 96, 685-694. http://dx.doi.org/10.2106/JBJS.M.00196

Murray, M. M., Martin, S. D., \& Spector, M. (2000). Migration of cells from human anterior cruciate ligament explants into collagen-glycosaminoglycan scaffolds Journal of Orthopedic Research, 18, 557-564.

Nag, H. L., \& Gupta, H. (2014). Anterior cruciate ligament reconstruction with preservation of femoral anterior cruciate ligament stump. Arthroscopy Techniques, 3, e575-e577. http://dx.doi.org/10.1016/j.eats.2014. 06.012

Nau, T., \& Teuschl, A. (2015). Regeneration of the anterior cruciate ligament: Current strategies in tissue engineering. World Journal of Orthopedics, 6, 127-136. http://dx.doi.org/10.5312/wjo.v6.i1.127

Pattee, G. A., Fox, J. M., Del Pizzo, W., \& Friedman, M. J. (1989). Four to ten year followup of unreconstructed anterior cruciate ligament tears. American Journal of Sports Medicine, 17, 430-435.

Petersen, W., Unterhauser, F, Pufe, T., Zantop, T., Sudkamp, N. P, \& Weiler, A. (2003). The angiogenic peptide vascular endothelial growth factor (VEGF) is ex,pressed during the remodelling of free tendon grafts in sheep. Archives of Orthopaedic and Trauma Surgery, 123, 168-174.

Rodriguez-Merchan, E. C. (2013). Regeneration of articular cartilage of the knee. Rheumatology International, 33, 837-845. http://dx.doi.org/10.1007/s00296-012-2601-3 
Snoeker, B. A., Bakker, E. W., Kegel, C. A., \& Lucas, C. (2013). Risk factors for meniscal tears: a systematic review including meta-analysis. Journal of Orthopaedic \& Sports Physical Therapy, 43, 352-367. http://dx.doi.org/10.2519/jospt.2013.4295

Song, G.-Y., Zhang, H., Zhang, J., Li, X., Chen, X. Z., Li, Y., \& Feng, H. (2013). The anterior cruciate ligament remnant: To leave it or not? Arthroscopy, 29, 1253-1262. http://dx.doi.org/ 10.1016/j.arthro.2013.03.078

Tohyama, H., Yoshikawa, T., Ju, Y. J., \& Yasuda, K. (2009). Revascularization in the tendon graft following anterior cruciate ligament reconstruction of the knee: its mechanisms and regulation. Chang Gung Medical Journal, 32, 33-39.

Xie, G. M., Huang Fu, X. Q., \& Zhao, J. Z. (2012). The effect of remnant preservation on patterns of gene expression in a rabbit model of anterior cruciate ligament reconstruction. Journal of Surgical Research, 176, 510-516. http://dx.doi.org/ 10.1016/j.jss.2011.10.035

Xie, J., Jiang, J., Huang, W., Zhang, Y., Xu, C., Wang, C., ... Sung, K. L. (2014). TNF- $\alpha$ induced down-regulation of lysyl oxidase family in anterior cruciate ligament and medial collateral ligament fibroblasts. Knee, 21, 47-53. http://dx.doi.org/10.1016/j.knee.2012.12.015

Yang, L., Tsai, C. M., Hsieh, A. H., Lin, V. S., Akeson, W. H., \& Sung, K. L. (1999). Adhesion strength differential of human ligament fibroblasts to collagen types I and III. Journal of Orthopedic Research, 17, 755-762.

Yoshikawa, T., Tohyama, H., Enomoto, H., Matsumoto, H., Toyama, Y., \& Yasuda. K. (2006). Expression of vascular endotelial growth factor and angiogenesis in patellar tendon grafts in the early phase after anterior cruciate ligament reconstruction. Knee Surgery Sports Traumatology Arthroscopy, 14, 804-810.

\section{Copyrights}

Copyright for this article is retained by the author(s), with first publication rights granted to the journal.

This is an open-access article distributed under the terms and conditions of the Creative Commons Attribution license (http://creativecommons.org/licenses/by/3.0/). 